Journal of Economics and Behavioral Studies

Vol. 2, No. 3, pp. 97-107, Mar 2011

\title{
Harnessing Explicit Knowledge
}

\author{
Wusheng Zhang1, *Mikyung Kim² \\ ${ }^{1}$ School of Management and Information Systems, Victoria University, Melbourne, Australia \\ 2School of Business IT and Logistics, RMIT University, Australia \\ *mikyung.kim@rmit.edu.au
}

\begin{abstract}
In the search for sustainable competitive advantage, managing knowledge is critical not only for large organizations but also for Small and Medium sized Tourism Enterprises (SMTEs) where limited resources and the lack of the strategic direction are prevalent. Findings from the literature review suggest that, in relative terms, SMTEs are less ready for implementing knowledge management projects than are large organizations. It is also suggested that SMTEs are in need of practical strategic guidance if they are to make the most of the, often under-exploited, knowledge within and available to their organizations. For the support of SMTEs' initial needs for knowledge management, this paper proposes a strategy aimed at harnessing explicit knowledge and strategic activities based on an extensive analysis of the literature. The proposed strategy contains actionable steps with timelines and milestones that can be implemented and modified iteratively by SMTEs, with in-built assessment and measurement mechanisms. The results of our study suggest that implementation itself can be flexible as well as iterative with no need for all the steps outlined for an improvement of the knowledge management process to be followed.
\end{abstract}

Keywords: Knowledge Management Strategy, Knowledge Activities, Small and Medium sized Tourism Enterprises (SMTEs)

\section{Introduction}

With the transition from industrial age economies based on physical inputs and capital towards knowledgebased economies, knowledge has become a vital organizational resource and a key to business progress. The ability of a nation's economy to generate knowledge and effectively employ it through productive organizations will determine a nation's success in international competition (Drucker, 1988). Many organizations especially those that are large and globalized have initiated a range of knowledge management projects and programmes. In a 2000 KPMG survey (McKellar, 2000) of 423 organizations, each with annual revenues exceeding US $\$ 270$ million in Europe, the United States, and elsewhere, approximately 75 percent were looking to knowledge management to play a significant role in improving competitive advantage, marketing, and customer focus. In the search for sustainable competitive advantage, managing knowledge has become critical not only for large organizations but also for SMTEs where the businesses deal with limited resources and lack a strategic direction.

The purpose of this paper is to introduce a knowledge management strategy and strategic activities applicable to SMTEs drawn from the analysis of relevant literature. The paper is organised as follows. First, it identifies unique characteristics of the tourism industry that necessitate the implementation of practical knowledge management strategies for competitive success in that industry. After following consideration of the treatment of knowledge management strategies in the literature, it introduces a strategy for harnessing explicit knowledge, along with some factors for its implementation and strategic activities likely to confer competitive advantage on SMTEs. Finally, the paper concludes with implications to managerial challenges that can be emerging.

\section{Methodology}

Secondary data were employed in order to explore current theory, in guiding development of the strategy. These secondary data were obtained from a review of the extant literatures. The literature review covered the field of Knowledge Management along with such relevant areas as Strategic Management, Tourism and 
Hospitality Management, and Organization Science, as well as Information Systems and Technology. Although the developing field of Knowledge management has been heavily influenced by developments in Information Systems and Technology, the range of influences reaches far beyond these two fields, resulting in the research taking a trans-disciplinary approach to gain a clear view of the state of knowledge management in theory and practice. In reviewing the literature, key words were used for searching and an iterative approach was adopted by integrating up-to-date new research findings as they became available. The literature review was drawn from three major sources: i) academic journals; ii) books and book chapters; and iii) conference proceedings.

In the literature, a wide range of frameworks and models for knowledge management has been recommended within the setting of large organizations. However, there has been little work to investigate the strategic options that could facilitate the practice of knowledge management in small and medium-sized tourism enterprises. The literature review identified the research gap with the evolution of knowledge management and of its overall theoretical construct being set in the context of large organizations. The lack of theoretical understanding of and empirical results from research into knowledge management in small and medium-sized tourism enterprises might be caused by the fact that knowledge management is a very multifaceted social phenomenon with no clear direction as to its application in other than the context of large organizations.

\section{The need for a knowledge management strategy in the tourism industry}

The tourism industry makes a significant contribution to Australia's economy, both in terms of the number of tourism organizations, and the proportion of the labour force employed by these organizations. In 2002 2003, tourism accounted for almost 4.2 percent of Australia's gross domestic product, employing 540,700 people representing 5.7 percent of total employment (ABS, 2003a). There are over 350,000 tourism-related businesses in Australia and most of these are small to medium-sized enterprises, with 90 percent of the businesses employing less than 20 staff (Australian Government, 2004). The Tourism Forecasting Council of Australia is expecting longer-term growth in visitations to Australia (Tourism Victoria, 2002). Less optimistically, the tourism industry has unique characteristics that impact on its potential sustainability. It is highly segmented, involving minimal capital investment, lower barriers to entry (Hughes, 1992; Baum, Wood, Morrison, McLennan, \& Baum, 1998), and is dominated by small and medium-sized organizations (ABS, 2003b) where the majority of businesses operate with limited resources (Storey, 1994; Ogden, 1998) and there is a high turnover of employees (King, Bransgrove, \& Whitelaw, 1998). In addition, it is an information intensive industry with the individualisation of mass tourism (Poon, 1993) and the heavy involvement of customers in the process of tourism experience such as selecting the destination, accommodation, transport, food, and entertainment as well as ancillary activities (such as banking/money exchange and visitor information services). In particular, small tourism businesses tend: to possess little in the way of competences and strategic direction relative to the advantages of new economies and technologies (Applebee, Ritchie, Demoor, \& Cressy, 2000; Lituchy \& Rail, 2000); and to have been slow in adopting formal and systematic knowledge management (Matlay, 2000; Uit Beijerse, 2000; McAdam \& Reid, 2001; Sparrow, 2001). All in all, these characteristics generate a challenge for the industry's longer-term sustainability. The findings suggest that, in relative terms, SMTEs are less ready for implementing knowledge management projects than are large organizations. It is also clear that SMTEs are in need of practical strategic guidance towards becoming genuine knowledge-managing organizations.

In such circumstances, managing organizational knowledge is imperative for SMTEs not only to tackle the reality of business disadvantage, but also to survive in a highly competitive industry. Knowledge management can be a powerful means for SMTEs. It can help to increase productivity, effectiveness and efficiency in operations. When time is short, the ability to make informed decisions rapidly on the basis of strategic knowledge is critical to sustained performance and to establishing an enduring competitive advantage. Knowledge management can be referred to the use of knowledge for competitive advantage. In this regard knowledge management is viewed as strategy, and knowledge relationship in terms of how knowledge and its effective management can confer strategic or competitive advantage on an organization (Grant, 1996; Boisot, 1998; Davenport \& Prusak, 1998; Teece, 1998). Where knowledge is regarded as a critical organizational 
resource then it follows that anything that can be done to improve the management of this resource, including the formulation of knowledge and knowledge-based strategies, is likely to contribute to organization survival and success. In strategic terms what is involved here is both strategy formulation and strategy execution. Although the difficulties of managing knowledge are well recognised, some aspects of knowledge such as culture, organizational structure, communication processes and information can be managed (Kakabadse, Kakabadse, \& Kouzmin, 2003). SMTEs need to look to these practical aspects of knowledge management if they are to prosper in the turbulent environment of a highly competitive, global and increasingly knowledge-based industry.

\section{Knowledge management strategies}

SMTEs seeking to maintain competitive advantage by managing their organizational knowledge will at some point have to proceed to the adoption of a knowledge management strategy. A knowledge management strategy is a general approach to defining operational strategy and objectives with specialised knowledge management principles and approaches (Srikantajah \& Koening, 2000). It depicts how an organization will manage its knowledge better for the benefit of that organization and ultimately its stakeholders (such as customers, suppliers, business partners, and employees as well as government and trade associations). SMTEs can gain several benefits from implementing a knowledge management strategy, which can be referred to Knapp's knowledge management benefits (1998). These benefits include some or all of the following: reduced loss of intellectual capital due to people leaving the company; reduced costs by decreasing the number of times the company must repeatedly solve the same problem, and by achieving economies of scale in obtaining information from external providers; reduced redundancy of knowledge-based activities; increased productivity by making knowledge available more quickly and easily; and increased employee satisfaction by enabling greater personal development and empowerment. As acknowledged by Knapp, the best rationale of all for the creation of a knowledge management strategy may be a strategic need to gain a competitive advantage in the marketplace. Every strategic position is linked to some set of intellectual resources and capabilities. That is, given what the firm believes it must do to compete, there are some things it must know and know how to do. Whether the strategic option is to compete through low cost or differentiation, the strategic choices that firms make regarding products, services, markets, technologies, and/or processes have a profound influence on the knowledge, skills and core competencies required to compete in the industry.

Strategic knowledge management can be approached from a number of directions, for example it can operate at the enterprise level, the departmental level and even to the point where it revolves around individual accountability for knowledge acquisition and transfer. One common choice of options for organizations involves an alternative between codification and personalisation strategies. Codification strategies operate on the basis of extracting knowledge from individuals and groups and codifying it in databases and intranets and other repositories (Hansen, Nohria, \& Tierney, 1999). Personalisation strategies by contrast, focus on knowledge that has not been codified and in all likelihood cannot be codified. The emphasis here is on individual and group communication, critically through human networks but also employing the telephone, electronic mail and videoconferencing technology. The choice between these strategic options will vary with the mission and competencies of the organization, as with the markets in which it operates, and there is evidence that for example, an overemphasis on codification through technology can adversely affect peoplecentred activities (Marchant, Kettinger, \& Rollins, 2003). Furthermore, although it is generally recommended that one or the other strategy be selected, there would seem to be a case for some form of hybrid approach involving judicious use of codification and personalisation. The two strategies co-exist in all organizations (Smith, 2004). Apart from anything else, only through personalisation are firms likely to succeed in tapping into potential sources of tacit knowledge.

Whatever the choice of strategy it will almost certainly be linked to a core set of knowledge processes including: knowledge acquisition, knowledge generation, knowledge dissemination, and knowledge use (Wiig, 1993; AP\&QC, 1996; Meyer \& Zack, 1996; Buowitz \& Williams, 2000). Depending on the organization's particular internal and/or external situation, the nature and extent to which knowledge features in its operations and strategies will differ. For example, some organizations may use knowledge to produce 
physical products/services while for others knowledge itself is the end product or service. The core set of knowledge processes can be described in more detail as follows:

Knowledge acquisition: Knowledge can be obtained internally or from various external sources. Internally obtained knowledge may be newly created within the organization or can be a combination of new and existing knowledge. The external sources may fall into three categories. The first category contains documented knowledge, such as reports, journals, books and on-line databases. The second category includes specialist knowledge drawn from consultants, researchers, experts, or through joint ventures or merger with other companies. The third category includes knowledge accumulated in such public forums, conferences, workshops, Internet discussion groups, and exhibitions.

Knowledge dissemination: Knowledge dissemination comprises the systemic processes of transferring existing and new knowledge to relevant employees in the organization. Disseminating knowledge enables not only knowledge of the organization to be widely spread amongst its members, but also to the public who need it to obtain access to the services or products provided by the organization. In disseminating knowledge, the adoption of push and pull mechanisms as delivery methods can be a useful component. The Push mechanism aims to provide a solution by sending information to employees (knowledge seekers) while pull is initiated by requests for information by the employees. However, simply delivering unsolicited information through the push mechanism to the employee's desktop may not be an effective way of dissemination if the individuals are not willing to convert it to knowledge. By contrast, knowledge can be generated even with the pull method if individuals are eager to do so.

Knowledge generation: The generation or discovery of new knowledge can be achieved through Research and Development, and experimentation, but also through such techniques as lessons learned, creative thinking, and the innovation process. It can also include the conversion of existing information into knowledge, as well as the conversion of for example, explicit knowledge into tacit knowledge to assist in the solution of business problems the improvement of organizational processes and the enhancement of capabilities and competences.

Knowledge use: Knowledge acquired, created or disseminated must be applied in business processes or projects otherwise the costs of its acquisition and creation will be wasted. Furthermore, the effective use of knowledge resources is a precondition of gaining advantages in market competition. The knowledge can be used in terms of decision-making, its embodiment into organizational artefacts such as databases and documents, and embedding within processes, products and/or services, and more generally to inform, empower and motivate employees.

One useful instrument for helping organizations to link their strategy, activities, and knowledge resources is strategy maps (Kaplan \& Norton, 2001) that provide a means for providing executives with a framework for describing and managing strategy. At the organization level, the strategy maps (Kaplan \& Norton, 2001) contain certain key components including: strategic themes, recipes for combining the intangible ingredients of skills, technologies and organizational climate with internal processes (e.g., revenue growth, profitability, sourcing and distribution) to create tangible outcomes, such as customer loyalty. The relative importance of these themes will vary for each organization, but as a general rule they provide a starting point for identifying those knowledge activities that may lead to competitive advantage. As strategy maps incorporate a number of important knowledge management elements, they can serve as a useful starting point for effective knowledge management.

\section{Harnessing explicit knowledge strategy \& strategic activities for SMTES}

To ensure long-term survival, management must make efficient and effective managerial decisions about the internal and external threats it faces. A knowledge management strategy provides one means for management to ensure that they have the right information to make these decisions and can help the firm maintain its competitive advantage in complex business milieus. Effective knowledge management involves a strategic commitment to improving the organization's effectiveness, as well as improving its opportunity 
enhancement. It can lead to the advance of the organization's mission and can confer strategic or competitive advantage on an organization (Grant, 1991). For that reason, the management of knowledge should be regarded as a strategic issue in assisting organizations to achieve and maintain competitive advantage.

The success of Nonaka and Takeuchi's book The Knowledge-creating Organization (1995) resulted in widespread adoption of the view that organizational knowledge was of two kinds, explicit and tacit. Although this has proved to be extremely useful both in a practical and a theoretical context, popularisation of this dichotomy actually resulted in a misrepresentation and hence, a misunderstanding of the original emphasis placed upon tacit knowledge by Polanyi (1996). Not only did Polanyi write about a third form, that is implicit knowledge, but also he regarded tacit and explicit knowledge as being related rather than as simple opposites (Polanyi, 1996). Within the knowledge management mainstream, however, the idea of the classic dichotomy gained hold. Accordingly, explicit knowledge is that which can be expressed in words, and can be easily communicated and shared in the form of hard data, scientific formulae, reports, articles, manuals and patents as well as in software and charts, and codified procedures. It can be obtained through study of job related material such as business journals or trade publications as well as in internal documentation.

Tacit knowledge, on the other hand, is knowledge that is informal, personal and hard to pin down. It is tied to the senses and to innate personal skills and intuitions. This is the kind of knowledge that is so subject to individual awareness that it cannot always be articulated (Nonaka \& Takeuchi, 1995). Where it can be shared this tends to occur in face-to-face situations, similar to the traditional master and apprentice relationship, and by the use of example, metaphor and narrative. The point could be made that with perhaps $90 \%$ of the knowledge in organizations being intangible, any focus on explicit knowledge seems likely to miss the great majority of value in the firm. Codified knowledge is almost inevitably going to turn out to be information that is widely available and accessible to competitors and thus, unlikely to prove of lasting strategic value. Individual and group experience and know-how on the other hand, particularly if leveraged through personalisation strategies seem much more likely to be effective in even the medium term.

In many business situations, the greater part of an individual's valuable and useful knowledge is tacit rather than explicit. However, the task of identifying, extracting and leveraging this kind of knowledge can be a daunting one and might well appear impractical in terms of time and other resources. This is likely to be the case for SMTEs contemplating perhaps the employment of outside consultants for advice and facilitation, or the purchase of suitable technology applications for codification, storage and content management. There would also be costs in learning time and in adjustment to the new systems. In the circumstances, the attractions of strategies that focused upon the identification and organization of critical explicit knowledge might seem obvious. Therefore, SMTEs should perhaps start with the low hanging fruit and aim for the acquisition, capture and sharing of explicit knowledge. Although all such exercises come with their own, not insignificant costs, the capture and management of explicit knowledge is largely a given, a part of the cost of doing business in tourism today. Meanwhile, the need for tacit knowledge and the attendant risks of loss and the costs of duplication, remain as powerful as ever. A few well-directed initiatives in a personalisation context, for example, the operation of communities of practice (Brown \& Duguid, 1998; Wenger, 1998), the creation of narrative databases and the maintenance of links with experts and former employees could go far to making a reality of a knowledge management strategy for SMTEs, one that supplemented an explicit core with a minimal tacit element.

Furthermore, all such initiatives and associated activities must form part of the firm's strategy rather than comprise standalone knowledge-related projects. The proposed strategy will contain actionable steps with timelines and milestones that can be implemented and modified iteratively by SMTEs, with in-built assessment and measurement mechanisms. This kind of approach can not only facilitate increased access to explicit knowledge by all employees, but also can gradually impact on efficient and effective business performance through their potential for aiding in problem solving, strategic planning, decision-making, and active learning. The results of our study suggest that implementation itself can be flexible as well as iterative with no need for all the steps outlined for an improvement of the knowledge management process to be followed. For example, in some cases, firms may start with an assessment of existing knowledge rather than 
by attempting to capture explicit knowledge or convert tacit knowledge into explicit form. For those firms who do have to adhere to the key strategic processes, however, the steps are expanded here as follows.

\section{Identifying knowledge}

The identification of knowledge that is of value and is also at risk of being lost in the organization is an essential step in implementing the knowledge management strategy, although identifying knowledge is difficult (Nonaka \& Takeuchi, 1995; Davenport \& Prusak, 1998; Hansen et al., 1999; Rowley, 2000; Coakes, 2004). According to Wiig's knowledge analysis (1993), there are a number of ways to identify knowledge: extracting what appears to be knowledge from obtained material by analysing transcripts and identifying themes, listening to an explanation, and selecting concepts for further consideration; abstracting extracted materials by forming a model or a theory; identifying patterns extracted by trend analysis; explaining relations between knowledge fragments by comparing and contrasting causal relations; verifying that extracted materials correspond to the meaning of original sources. Identifying which knowledge is valuable and how it will support the firm's product and market positions are worthwhile elements at the beginning of the execution of the strategy.

In order to identify the knowledge required, an SMTE could first check its existing knowledge. Having done so, the next action would be identifying the extent to which it is being utilised. Very useful is of the performance of a gap analysis to identify any gaps between what the firm knows and what it needs to know. The gap analysis provides SMTEs with a means of determining the current and desired states of knowledge resources and methods. It can also serve discovery not only of a knowledge gap but also of a strategic gap. Understanding knowledge requirements from a strategic perspective (Zack, 1999a) will enable the SMTE to identify which knowledge is critical. Aligning those knowledge requirements and developing the findings of knowledge gap analysis into a roadmap linking explicit knowledge resources and the processes which produce and make use of them, can be another useful approach to bring about the strategy. While identification of the knowledge might be a practical starting point, some element of prioritisation is necessary in relation to the sheer volume of explicit knowledge and such factors as relevance, urgency, time and cost.

\section{Organising the knowledge}

Once the knowledge is identified, its organization in a structured manner increases reusability by enabling not only current but also future use. The process of organising the knowledge involves storing, classifying, and indexing. Storing the knowledge in repositories is important for knowledge retention, whereas indexing the knowledge has a role in directing it to employees who need it. Classifying the knowledge refers to categorising the structure of the contextual knowledge and the content of the knowledge. It could begin by developing and structuring taxonomy of knowledge with a choice of a method for taxonomy development, for example, in terms of computerised vs non-computerised, recorded vs non-recorded, and known to software vs not-known to software. Knowledge can also be characterized as existing in collections of forms such as: practical, intellectual, small talk, spiritual and unwanted (Machlup, 1980); symbolic, embodied, embrained and encultured (Collins, 1993); public knowledge, shared expertise, and personal knowledge (Wiig, 1993);

core, advanced and innovative (Zack, 1999b). Some classifications use a dichotomy to describe one type of knowledge and its opposite such as codified versus personalised knowledge (Zack, 1999a) and tacit versus explicit knowing (Polanyi, 1996; Nonaka \& Takeuchi, 1995). Classifying an organization's knowledge is closely related to the first step of identifying knowledge in terms of looking at the organization's knowledge position.

In organising knowledge, information technology can be seen as an important facilitator, which enables knowledge management to happen by providing tools needed to share knowledge and by aiding in a process of knowledge activities. Information technology plays an important role as an enabler of knowledge processes aimed at capturing, storing, sharing, and distributing knowledge. It can be essential for the digital capture, storage, retrieval and distribution of explicit knowledge in databases and repositories (Zack, 1999a), as well as a collaborative communication device, through e-mail systems and video-conferencing. It is primarily used to store and transfer explicit forms of knowledge. Although face-to-face interaction and verbal 
conversation are often more efficient in sharing and transferring tacit knowledge, information technology is more useful for the transmission of explicit knowledge and information. Many organizations employ information technology in one form or another to manage their intellectual capital (McKellar, 2000), where groupware and intranet support knowledge access and exchange within organizations (Ruggles, 1998). Groupware is a type of software that is designed to help teams that are geographically dispersed and need to work together. Intranets are private networks and emphasise internal information constructing links among organizations and their employees. In addition, a study from AP\&QC (1996) shows that organizations embarking in knowledge management efforts generally rely, for accomplishing their goals, on the setting up of a suitable information technology infrastructure. It would be a good idea for SMTEs to check existing technology and make a baseline of the technology before investing on any new technology.

\section{Making the knowledge accessible}

The knowledge identified and organised must be made accessible to the individual members of the organization. Sharing explicit knowledge among employees, provided the actually use it, can grow the supply of knowledge and improve the value-adding capacity of employees. Knowledge becomes more powerful and valuable as the number of people accessing it increases (Nonaka and Takeuchi, 1995). Knowledge needs to be shared throughout the organization because new organizational knowledge starts with individuals (Inkpen, 1996), otherwise it will have limited impact on organizational effectiveness. But the hardest part is driving knowledge sharing to the centre of an organization and this hinges on the employees being willing to share their knowledge, and to learn from the knowledge made available. For example, the development of a knowledge directory will be of no use in an organization that is resistant to knowledge sharing. Because actual sharing is most likely voluntary, the challenge is to create a culture where people are eager to share their knowledge.

Thus, encouraging employees through interaction and collaboration to share the knowledge is the most practical approach in making the knowledge accessible, both when attempting to communicate tacit knowledge between individuals and convert tacit knowledge into explicit knowledge. The underlying rationale of encouraging employees to share knowledge is to retain and leverage a great deal of useful organizational knowledge. When employees leave an organization, they take their knowledge with them (Davenport \& Prusak, 1998; Scarbrough, Swan, \& Preston, 1999). Knowledge sharing can operate through regular contact and distribution to employees on the basis of their need and interest and the requirements of the firm. It includes transfer and dissemination of best practices and lessons learned. It could be tactically practised in SMTEs by: ongoing employee training, making the industry standard procedures and policies available to employees, arranging regular staff meetings, and establishing the mentor-apprentice relationship within the organization. It could also be achieved by making valuable knowledge from external sources accessible through feedback from colleagues, attending tourism industry conferences, forums, events, and exhibitions.

\section{Exploiting the knowledge}

Putting the explicit knowledge assets of the company to use in search of a competitive advantage is an increasingly critical challenge for SMTEs. Knowledge assets are essentially encapsulated in the employees, customers and other stakeholders, and in the processes and procedures, that support the supply of goods and services to the market and enable to business to operate and generate value and profits. Therefore, making as much of this knowledge as possible explicit and accessible for use in the business is a critical challenge for SMTEs. The main purpose of exploiting knowledge is to add value to business outcomes by turning previously individual or group knowledge into a corporate asset. SMTEs can use this knowledge in decision-making, solving problems, products and service development, improving customer service quality and routine service procedures, and developing new or alternative service operations. The effort of exploiting the knowledge could be attempted by enabling organizational culture (i.e., valuing and encouraging the knowledge use for adding value to the organization) including reword/recognition systems. 
The success of such knowledge management initiatives can only be realised in the context of organizational cultures that enable knowledge management by valuing knowledge and knowledge sharing and providing appropriate reward/recognition systems to encourage the desired behaviours. In recognising the complexity of knowledge management many leading authors (Garvin, 1993; Zack, 1999b; Drucker, 2001) acknowledge the key significance of cultural issues. Culture is a pattern of shared basic assumptions (Schein 1997, 1999), an enduring set of values, beliefs and assumptions that characterise organizations and their members (Cameron \& Quinn, 1999). Over time organizations learn what works and what does not work. As the lessons become second nature, they become part of the organizational culture and new employees learn the culture from their mentors along with know-how. The impact of corporate culture on an organization is difficult to measure. However, strong culture generally can be associated with strong, measurable bottom-line results including net income, return on invested capital, and yearly increases in stock price (Hibbard, 1998). Without the benefit of a culture that recognises, encourages, and rewards the use of the knowledge for the organization, the effective and consistent exploitation of knowledge is unlikely to occur.

\section{Assessing and measuring the effects of knowledge management}

As with other resources in a business, it is important that the performance of the knowledge management operation can be assessed and to some extent at least, measured. Measuring and assessing the effects of knowledge management are necessary to achieve optimum business performance results. These activities will help to track the effort and activities in knowledge management where progress and performance results of knowledge management should be measurable through all considered activities in SMTEs. There can be many types of business performance, such as return-on-investment, in relation to measuring knowledge management. It is suggested that SMTEs be to check the effect through improved customer service quality exceeding their expectations thus improved customer satisfaction, increased customer loyalty, and new knowledge embedded in product/services development. One of the ways to do an assessment may begin by assessing the quality and strategic value of its knowledge relative to its competition. The knowledge activities/processes themselves should also be assessed to support its continuous development as the conduct of knowledge management involves manoeuvring organizational knowledge through executing knowledge management activities that operate on the organization's knowledge resources. The assessment of the activities/processes and knowledge/core competencies helps with requirements, development and strategy mapping. Accordingly, both measurement and assessment are important for SMTEs to map new areas of improvement and new actions plans.

In line with the popular maxim that to manage is to measure, many organizations have attempted to measure the outcomes of knowledge management programs (Coakes, 2004). Indeed there are now so many proprietary methods for the measurement of such projects, from the Balanced Scorecard to a host of more recent techniques, that they can be categorised according to purpose and structure. Apart from the fact that many of these systems seem to apply only in the context of specific organizations, there is a general difficulty in separating knowledge inputs and outputs from those of other resources in the identification process, and also in the assignment of reliable values to variables. There are no accepted standards as to which variables to use or even which categories of variables to consider, except for some agreement on how to approach the identification of suitable variables for a particular organization. Variables need to be defined precisely in order to avoid confusion. If the dimension of a proposed variable is unclear, a more accurate specification needs to be called for.

Whereas the potential value of measuring either knowledge itself or as embodied in intellectual assets is recognised, there is also clear acceptance of the difficulties and the potential risks involved (Eccles, 1991; Bohn, 1994; Brooking, 1996; Kaplan \& Norton, 1996; Stewart, 1997; Edvinsson \& Malone, 1997; Roos \& Roos, 1997). As with other advanced knowledge management operations, measurement may well be regarded as something of a luxury in the circumstances of SMTEs. Assuredly, they will need to have some indication of return-on-investment and the related cost-benefit implications of the knowledge management exercise, but for SMTEs that other maxim about the best being the enemy of the good may well apply. Whereas, traditional methods of reporting and accounting generally fail to account for intellectual capital, the costs of applying alternative methods could well outweigh any potential benefits. A more fruitful approach may well be that of 
striving to improve the working environment and stakeholder relationships in order to promote desirable knowledge-related behaviours and hence, put in place what could be de facto, if indirect, metrics for intellectual capital.

\section{Implications and conclusion}

The challenge for SMTEs in the knowledge economy is one of managing their organizational knowledge where increasingly this process is seen as crucial to organizational success and survival. SMTEs that are able to harness knowledge better than their competitors are more likely to gain sustainable competitive advantage. This paper has introduced a strategy for harnessing explicit knowledge in organizations, along with some strategic activities, which SMTEs can adopt to facilitate effective knowledge management. In the search for competitive advantage, this strategy focuses on the practical steps of identifying, organising, making accessible and exploiting explicit knowledge as well as measuring and assessing the effects of knowledge management. These fundamental but nonetheless, potentially strategic activities should be utilised iteratively and dynamically. Although it is intended to support knowledge management initiatives in SMTEs, this approach to strategy can be extended to other domains. While to some extent a generic approach, in order for the effective business performance this strategy must be applied within the context, and the contextual implications of the particular situation of individual SMTEs. Furthermore, effectively communicating the strategy and the strategic activities with employees is as important as arriving at the goal for which managers/owners have opted. As knowledge management is people centred, employee participation and understanding of the management's intentions are essential to making a reality of SMTEs' visions and strategies.

\section{References}

ABS. (2003a): Australian National Accounts: Tourism Satellite Account 2001-2002, Cat No. 5249.0. Canberra: Australian Bureau of Statistics.

ABS. (2003b): Small Business in Australia 1999. Canberra: Australian Bureau of Statistics.

Applebee, A., Ritchie, B., Demoor, S., \& Cressy, A. (2000): The ACT Tourism Industry Internet Study: attitudes, perceptions and adoption. Canberra: Centre for tourism research, University of Canberra.

AP\&QC International Benchmarking Clearinghouse (1996): Knowledge management: Consortium benchmarking study final report. Houston: American Productivity \& Quality Centre.

Australian Government (2004): Knowledge Intensive Service Activities in the Software Industry. Canberra: Department of Industry Tourism and Resources.

Baum, T., Wood, R., Morrison, A., McLennan, R., \& Baum, B. (1998): International Benchmarking and Best Practice Study of Training and education for Tourism, Glasgow: Scottish Tourism Research Unit, University of Strathclyde.

Bohn, R. (1994): Measuring and Managing Technological Knowledge, Sloan Management Review, 61 - 73.

Boisot, M. H. (1998). Knowledge Assets: Securing Competitive Advantage in the Information Economy. New York: Oxford University Press.

Brooking, A. (1996: Introduction to intellectual capital. Cambridge, England: The Knowledge Broker Ltd.

Brown, J., \& Duguid, P. (1998): Organizing knowledge, California Management Review, 40(3): 90-112.

Bukowitz, W., \& Williams, R. (2000): The knowledge management field book. London: Prentice Hall.

Cameron, K. S., \& Quinn, R. E. (1999): Diagnosing and changing organizational culture. Reading: AddisonWesley.

Coakes, E. (2004): Knowledge Management-a Primer, Communications of the Association for Information Systems, 14: 406.

Collins, H. M. (1993): The structure of knowledge, Social Research, 60 (1): 96-116.

Davenport, T. H., \& Prusak, L. (1998): Working knowledge: How organizations manage what they know. Boston, MA: Harvard business School Press.

Drucker, P. F. (1988): The coming of the new organization, Harvard Business Reviews, 45-53.

Drucker, D. (2001): Knowledge mgm't revised-theory doesn't equal practice, Internet Week, 846.

Eccles, R. (1991): The Performance Measurement Manifesto, Harvard Business Review, 131-137. 
Edvinsson, L., \& Malone, M. S. (1997): Intellectual Capital: Realizing Your Company's True Value by Finding its Hidden Brainpower. New York: Harper Business.

Fletcher, L. (1997): Information retrieval for intranets: The case of knowledge management, Document World, 2, 32-34.

Garvin, D. A. (1993): Building a learning organization, Harvard Business Review, 71: 78-91.

Grant, R. M. (1991): Prospering in ally competitive environments: organizational capability as knowledge integration, Organization Science, 7:375-387.

Grant, R. M. (1996): Toward a Knowledge-Based Theory of the Firm, Strategic Management Journal, 17: 109.

Hansen, M. T., Nohria, N., \& Tierney, T. (1999): What's your strategy for managing knowledge? Harvard Business Review, 77(2): 101-116.

Hibbard, J. (1998): Cultural Breakthrough, InformationWeek, September.

Hughes, H. (1992): Economics for the Hotel and Catering Industry. Hutchinson, London.

Kakabadse, N., Kakabadse, A., \& Kouzmin, A. (2003): Reviewing the knowledge management literature: towards a taxonomy, Journal of Knowledge Management, 7(4): 75-91.

Kaplan, R. S., \& Norton, D. P. (1996): The Balanced Scorecard. Boston, MA: Harvard Business School Press.

Kaplan, R. S., \& Norton, D. P. (2001): The Strategy-Focused Organization. Boston, MA: Harvard Business School Press.

King, B., Bransgrove, C., \& Whitelaw, P. (1998): Profiling the Strategic Marketing Activities of Small Tourism Businesses, Journal of Travel and Tourism Marketing, 7(4): 45-59.

Knapp, E. M. (1998): Knowledge management, Business and Economic Review, 44 (4).

Levinthal, D., \& March, J. (1993): The myopia of learning, Strategic Management Journal, 14, 95-112.

Lituchy, T., \& Rail, A. (2000): Bed and Breakfasts, Small Inns, and the Internet: The impact of technology on the globalisation of small businesses, Journal of International Marketing, 86-97.

Machlup, F. (1980): Knowledge: its creation, distribution, and economic significance. New Jersey: Princeton University Press.

Marchant, D. A., Kettinger, W. J., \& Rollins, J. D. (2000): Information Orientation: People, Technology and the Bottom Line, Sloan Management Review, 41(4): 69-80.

Matlay, H. (2000): Organizational learning in small learning organizations: an empirical overview, Education and Training, 42(4), 202-211.

McAdam, R., \& Reid, R. (2001): SME and large organization perceptions of knowledge management: comparisons and contrasts, Journal of Knowledge Management, 5(3):231-241.

McKellar, H. (2000). KPMG releases: KM report, KM World, March.

Meyer, M., \& Zack, H. M. (1996): The design and implementation of information products, Sloan Management Review, 37(3): 43-59.

Nonaka, I., \& Takeuchi, H. (1995): The knowledge-creating company. Oxford University Press.

Ogden, P. (1998): Comment: Benchmarking and best practice in the small hotel sector, International Journal of Contemporary Hospitality Management, 10(5): 189-190.

Polanyi, M. (1996): The tacit dimension. London, UK: Routledge \& Kegan Paul.

Poon, A. (1993): Tourism, Technology and Competitive Strategies. CAB International, Wallingford: Kapitel 5.

Roos, G., \& Roos, J. (1997): Measuring your Company's Intellectual Performance, Long Range Planning, 30(3): 413-427.

Rowley, J. (2000): Knowledge organization for a new millennium: Principles and processes, Journal of Knowledge Management, 4(3): 217-223.

Scarbrough, H., Swan, J. \& Preston, J. (1999): Knowledge management: A literature review. London: Institute of Personnel and Development.

Schein, E. (1997): Organizational Culture and Leadership (2nd Ed). San Francisco: Jossey-Bass.

Schein, E. (1999): The corporate culture survival guide. San Francisco: Jossey-Bass.

Smith, A. D. (2004): Knowledge Management Strategies: a Multi-Case Study, Journal of Knowledge Management, 8: 6-16.

Sparrow, J. (2001): Knowledge management in small firms, Knowledge and Process Management, 8(1): 3-16.

Srikantajah, T. K., \& Koening, M. E. D. (2000): Eds. Knowledge Management for the Information Professional. Medford, New Jersey: ASIS Monograph Series.

Stewart, T. A. (1997): Intellectual capital: The new wealth of organizations. New York, Currency: Doubleday. Storey, D. (1994): Understanding the Small Business Sector, London, Routledge. 
Teece, D. J. (1998): Capturing Value from Knowledge Assets: The New Economy, Markets for Know-How, and Intangible Assets, California Management Review, 40, 55.

Tourism Victoria (2002): Strategic Business Plan 2002-2006 Melbourne, Tourism Victoria.

Uit Beijerse, R. P. (2000): Knowledge management in small and medium-sized companies: Knowledge management for entrepreneurs, Journal of Knowledge Management, 4(2): 162-179.

Wenger, E. (1998): Communities of Practice: Learning, Meaning and Identity. Cambridge: Cambridge University Press.

Wiig, K. (1993): Knowledge management foundations: Thinking about Thinking-How People and Organizations Create, Represent and Use Knowledge. Arlington, TX: Schema Press.

Zack, M. H. (1994): Electronic messaging and communication effectiveness in an ongoing work group, Information \& Management, 26(4): 231-241.

Zack, M. H. (1999a): Managing codified knowledge, Sloan Management Review, 40(4): 45-58.

Zack, M. H. (1999b): Developing a knowledge strategy. California Management Review, 41(3): 125-146. 